\title{
Letter of Retraction
}

It has come to our attention that the a manuscript published in CIM: JianXin J, Cha Y, ZhiPeng L, Jie X, Hao Z, Meiyuan C, ChengYi S "GOLP3 is a predictor of survival in patients with hepatocellular carcinoma” Clin Invest Med. 2014 Aug 1;37(4):E233-42 contains text identical to a manuscript published in Tumour Biology: Hu GS, Li YQ, Yang YM, Shi W, Liao AJ, Yao YH, Zeng B, Yuan J "High expression of Golgi phosphoprotein3 is associated with poor survival in patients with hepatocellular carcinoma" Tumour Biol. 2014 Sep;35(9):8625-32. doi: 10.1007/s13277-014-2105-8. Epub 2014 May 28. For this reason, the publication in CIM has been retracted.

Jonathan Angel, MD

Editor, CIM

Clin Invest Med 2015; 38 (3): E142.

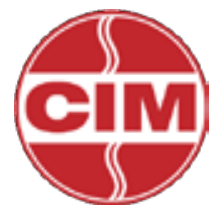

